\title{
Jean-Jaques Lefrère, Les Loisirs de la poste: lettres inédites d'Ephraïm Mikhaël
}

\author{
Isabella Giovinazzo
}

\section{(2) OpenEdition}

\section{Edizione digitale}

URL: https://journals.openedition.org/studifrancesi/38083

DOI: 10.4000/studifrancesi.38083

ISSN: 2421-5856

\section{Editore}

Rosenberg \& Sellier

\section{Edizione cartacea}

Data di pubblicazione: 15 décembre 2004

Paginazione: 637

ISSN: 0039-2944

\section{Notizia bibliografica digitale}

Isabella Giovinazzo, «Jean-Jaques Lefrère, Les Loisirs de la poste: lettres inédites d"Ephraïm Mikhaël», Studi Francesi [Online], 144 (XLVIII | III) | 2004, online dal 30 novembre 2015, consultato il 08 mai 2021. URL: http://journals.openedition.org/studifrancesi/38083; DOI: https://doi.org/10.4000/studifrancesi. 38083

Questo documento è stato generato automaticamente il 8 mai 2021.

\section{(c)}

Studi Francesi è distribuita con Licenza Creative Commons Attribuzione - Non commerciale - Non opere derivate 4.0 Internazionale. 


\title{
Jean-Jaques Lefrère, Les Loisirs de la poste: lettres inédites d'Ephraïm Mikhaël
}

\author{
Isabella Giovinazzo
}

\section{NOTIZIA}

JEAN-JAQUES LEFRÈRE, Les Loisirs de la poste: lettres inédites d'Ephraïm Mikhaël, «Histoires Littéraires», 2003 no. 15, pp. 82-148.

1 La rivista pubblica per la prima volta testi conservati presso la Houghton Library dell'Università di Harvard, provenienti dalla collezione del bibliofilo Henri Soffrey, già collezionista degli archivi su Rimbaud di Rodolphe Darzens, destinatario delle lettere qui pubblicate, scritte tra il 1884 e il 1888. Ad introdurre la corrispondenza, l'A. propone un profilo biografico del poeta, con la ricostruzione delle sue amicizie, alcune delle quali risalgono agli anni degli studi, come lo stesso incontro con Darzens, le sue frequentazioni letterarie e i suoi legami con i contemporanei e le figure di primo piano della scena letteraria, la partecipazione alle pubblicazioni dell'epoca, la sua carriera, presto interrotta dalla morte prematura e la sua collocazione nel movimento poetico coevo. 